\title{
Basic Educational Principles \& Awareness about Practices of Bio Safety among Health Care Students \\ Rajajeyakumar $\mathbf{M}^{1 *}$ and Janitha $\mathrm{A}^{2}$
}

${ }^{1}$ Department of Physiology, Chennai Medical College Hospital \& Research Centre, Irungalur, Trichy - 621105, Tamil Nadu, India ${ }^{2}$ Senior Medical Officer, Bharat Heavy Electricals Limited, Trichy-620014, Tamil Nadu, India

\section{Introduction}

Biohazards are pathogenic microorganisms capable of selfmultiplication. In this view, any microbe that can produce disease in humans or animals is considered a biohazard. Potentially bio hazardous agents which may produce silent infections must be considered bio hazardous. Materials that may harbor infectious agents (ex. human blood, body fluids, tissues, and cells) must also be considered bio hazardous [1].

\section{Aims and Objectives}

- Identify the potentially hazardous biological materials, the risks associated with their use, and how to minimize risk and to protect against or prevent release or exposure.

- To provide effective technical expertise in situations involving potentially hazardous biological materials.

- Identify, locate, and efficiently use key biosafety resources.

- To create current levels of awareness and risk perception on biosecurity among young future researcher.

\section{Definitions}

Bioethics: A branch of applied ethics that studies the value implications of practices and developments in the life sciences and medicine [2].

Biosafety: Laboratory biosafety describes the containment principles, technologies, and practices that are implemented to prevent unintentional exposure to biological agents and toxins, or their accidental release [3].

Biosecurity: Protection, control, and accountability measures implemented to prevent the loss, theft, misuse, diversion, or intentional release of biological agents and toxins and related resources, as well as unauthorized access to, retention, or transfer of such material [4].

\section{Biosafety method provides environmental health and safety}

Biosafety is a set of specialized techniques for proper handling and disposal of infectious organisms or biological material. Our aim to specify controls and safe handling practices for microorganisms (viruses, bacteria, fungi, rickettsia, mycoplasma, protozoans, multicellular parasites and prions), biological toxins, recombinant or synthetic nucleic acid molecules.

\section{Biosafety and the profession}

A biosafety professional develops and participates in programs to promote safe microbiological practices, procedures, and proper use of containment equipment and facilities; stimulates responsible activities among workers; and provides advice on laboratory design. Regardless of background and education, biosafety professionals must develop knowledge of the principles of epidemiology, disease transmission patterns, risk-assessment and risk management, disinfection and sterilization, disease prevention, aerobiology and environmental control. Biosafety professionals include Microbiologists, Industrial Hygienists, Biologists, Engineers, Molecular Biologists, Veterinarians, Occupational Health Professionals, Environmental Health Professionals, Clinical Health Care Professionals, and Biosecurity Professionals.

\section{Institutional biosafety program}

Institutional Biosafety Program monitors all laboratory activities involving biohazards, infectious or biologically-derived infectious materials, and toxins that present a risk or potential risk to the environment. Specifically biohazards can injure the health of humans or animals, either directly through individual infection or to large populations in nature when released from a controlled situation.

\section{Role of biosafety programmer regulating environmental health \& safety}

The Biosafety Programme officer is responsible for developing, implementing, coordinating and maintaining a comprehensive biosafety program. This includes responsibility for the Biosafety Program, the Occupational Health Program for workers exposed to research animals, the Blood borne Pathogens program, and coordination of the Institutional Biosafety Committee. The Biosafety research person promotes safe practices and procedures in biological research, stimulates responsible activities among faculty, staff and students, and provides education and guidance for the safe conduct of biological research.

\section{Bio risk reduction}

Bio risk reduction combines expertise and advice on highconsequence pathogens with guidance and training on safe handling and control of disease agents that pose significant health risks, with potential for adverse economic impact and public concern. Experience is gained through outbreak response, managing clinical and laboratory environments, networking with subject matter experts. Events can be of natural, accidental or deliberate origin; therefore provision of specific knowledge and translated practices prepares responsible partners to address the unexpected. The goal of bio risk reduction is to ensure that

*Corresponding author: Rajajeyakumar M, Department of Physiology, Chennai Medical College Hospital \& Research Centre, Irungalur, Trichy-621105, Tamil Nadu, India, Tel: 09751382650; E-mail: rajakumar60@gmail.com

Received December 01, 2014; Accepted December 01, 2014; Published December 18, 2014

Citation: Rajajeyakumar M, Janitha A (2015) Basic Educational Principles \& Awareness about Practices of Bio Safety among Health Care Students. J Biosafety Health Educ 2: e117. doi:10.4172/2332-0893.1000e117

Copyright: () 2015 Rajajeyakumar M, et al. This is an open-access article distributed under the terms of the Creative Commons Attribution License, which permits unrestricted use, distribution, and reproduction in any medium, provided the original author and source are credited. 
Citation: Rajajeyakumar M, Janitha A (2015) Basic Educational Principles \& Awareness about Practices of Bio Safety among Health Care Students. J Biosafety Health Educ 2: e117. doi:10.4172/2332-0893.1000e117

Page 2 of 2

current scientific knowledge is maintained in order to apply the most appropriate guidance for treatment, control, and safety to mitigate the risks regardless of the source of the disease event.

\section{References}

1. Baldwin CL, Runkle RS (1967) Biohazards symbol: development of a biological hazards warning signal. Science 158: 264-65.
2. Ruth Chadwick (2014) Bioethics in China Revisited. Bioethics. 28: ii-ii 207-268.

3. Declan Butler (2014) Biosafety controls come under fire. Nature 511: 515-516.

4. Atlas RM, Dando M (2006) Biosecurity and Bioterrorism: Biodefense Strategy, Practice, and Science. 4: 276-286. 